\title{
A new manoeuvre for overcoming extreme brachiocephalic artery tortuosity in radial coronary angiography
}

\author{
Murat Başkurt, Kudret Keskin
}

Cardiology Department, Medicana Hospitals Bahçelievler, Istanbul, Turkey

Postep Kardiol Inter 2014; 110, 3 (37): 211-212 DOI: $10.5114 /$ pwki.2014.45152

The radial approach has a class II recommendation in percutaneous coronary interventions for decreasing access site complications [1]. Radial coronary intervention is being used more in recent years. The radial approach has some limitations that are not seen in the femoral approach. Severe subclavian artery tortuosity and distal origin of the innominate artery result in a decreased forward force and increased friction during the progression of the wire or guide in the ascending aorta, which usually resolves with the use of a hydrophilic wire combined with deep breathing [2]. However, when subclavian artery and severe brachiocephalic artery tortuosity combines, the cannulation of the coronary arteries may be difficult.

A 75-year-old male patient had moderate-degreesubclavian and severe brachiocephalic tortuosity that allowed left coronary cannulation and angiogram with a Judkins $L 3.5$ diagnostic catheter from the right radial approach (Figures 1 A, B). However, it was impossible to advance the right Judkins catheter down to the right sinus Valsalva and rotate it with even stiffer wires with

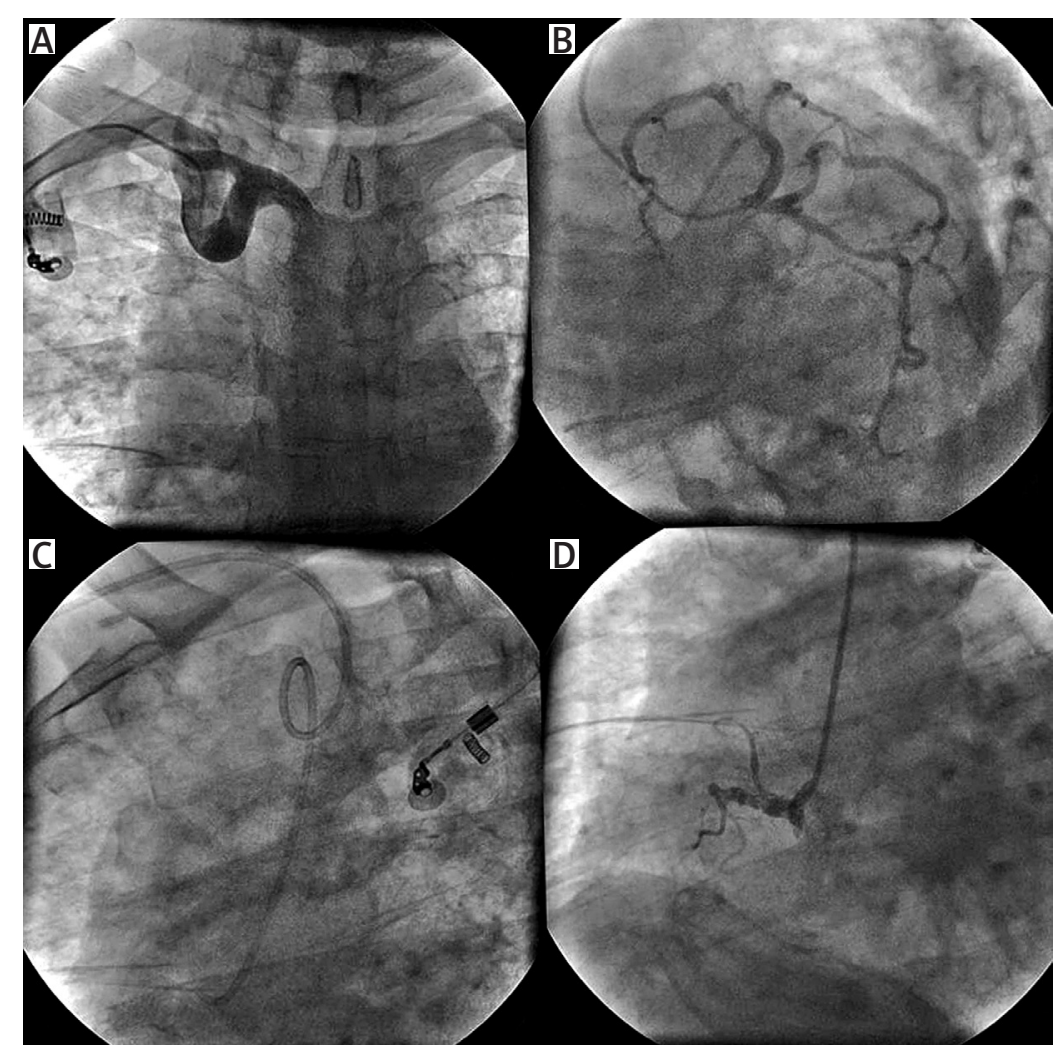

Figure 1. Coronary angiogram from right radial approach is seen in the patient with extreme brachiocephalic artery tortuosity. A - Severe subclavian and brachiocephalic artery tortuosity is seen. B - Left main coronary artery cannulation was easily done with Judkins 3,5 left coronary catheter. $\mathbf{C}$ - Advance the right judkins catheter down to right sinus valsalva and rotate was impossible with even stiffer wires. D - After the right arm was held by the technician cranially it was possible to cannulate the right coronary artery 

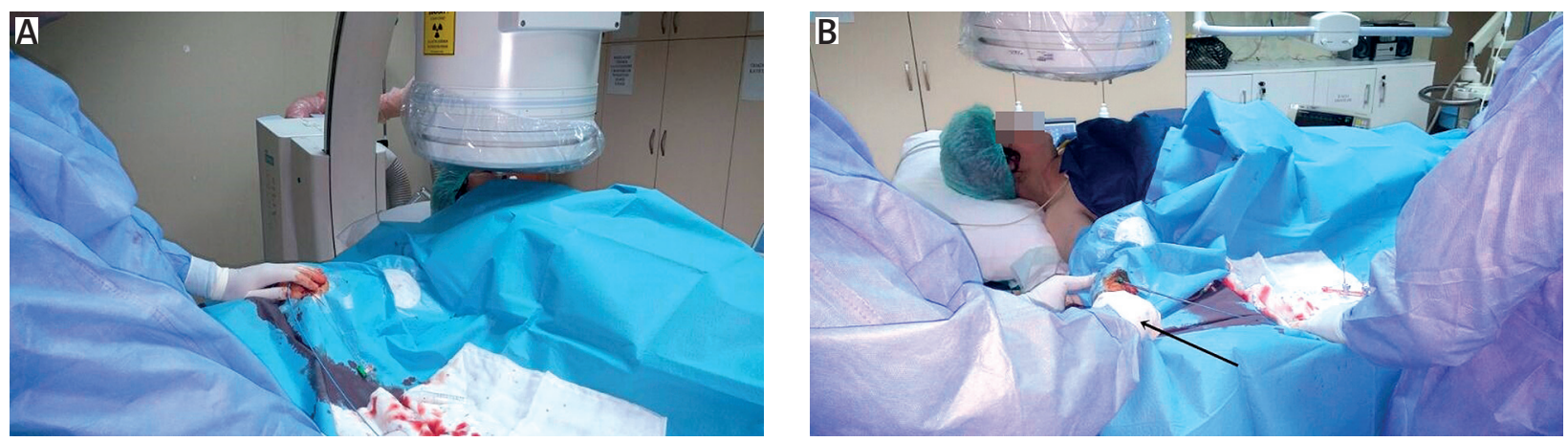

Figure 2. The manouevre is seen. A - At first the patient's right forearm is positioned $10-20^{\circ}$ caudally in the craniocaudal plane $\left(70-80^{\circ}\right.$ caudal angle with the body) as the first anatomic position when performing right radial coronary angiography. $\mathrm{B}$ - Technician hold the patient's right forearm and pulled the right arm to $50-60^{\circ}$ cranially and a slightly superior than the first position. After the manoeuvre, the right arm was held by the technician in approximately $40-50^{\circ}$ cranially in craniocaudal plane

the above manoeuvre (Figure $1 \mathrm{C}$ ). Then the technician held the patient's right forearm, which was positioned $10-20^{\circ}$ caudally in the cranio-caudal plane (70-80-degree caudal angle with the body) and pulled the right arm to $50-60^{\circ}$ cranially and slightly superior to the first position (Figures $2 \mathrm{~A}, \mathrm{~B}$ ). Our aim was to correct some degree of the tortuosity of the subclavian and brachiocephalic arteries by using changes in the body and extremity positions to create a more flat path for the catheter to move along. After the manoeuvre, the right arm was held by the technician approximately $40-50^{\circ}$ cranially in the cranio-caudal plane, so that it was possible to advance the right Judkins catheter through the entire ascending aorta and easily rotate it clockwise for RCA cannulation (Figure 1 D). To our knowledge, this manoeuvre has not been described before for similar situations in right radial coronary angiography. Changes in anatomic positions of the body may help the interventional team in handling anatomical problems of the vessels.

\section{References}

1. Levine GN, Bates ER, Blankenship JC, et al. 2011 ACCF/AHA/SCAI Guideline for Percutaneous Coronary Intervention: a report of the American College of Cardiology Foundation/American Heart Association Task Force on Practice Guidelines and the Society for Cardiovascular Angiography and Interventions. Circulation 2011; 124: e574-651.

2. Nguyen N, Colombo A, Hu D, et al. Practical handbook of advanced interventional cardiology: tips and tricks. $3^{\text {rd }}$ ed. Nguyen N, Colombo A, Hu D, et al. (ed). Blackwell Publishing, Massachusetts 2008. 